\title{
Avaliação do impacto do marco \\ regulatório vigente na matriz de correlação dos indicadores- chave de risco em concessionárias de geração
}

\begin{abstract}
Otavio Piacentini
Mauro Mastella*

* Orientador. Instituição atual: Universidade Federal de Ciências da Saúde de Porto Alegre. Departamento de Ciências Exatas e Sociais Aplicadas. Rua Sarmento Leite, 245 - Sala 400C - Porto Alegre (RS) - CEP 90050-170.

E-mails: otaviojp@gmail.com mauro@ufcspa.edu.br
\end{abstract}

Universidade Estadual do Rio Grande do Sul, Especialização em Gestão Pública, Porto Alegre, RS, Brasil.

Recebido em: 12 jun. 2017. Revisado em: 3 nov. 2017 Aceito: 22 nov. 2017.

DOI: http://dx.doi.org/10.21674/2448-0479.42.218-229

\section{Resumo}

Esta pesquisa aborda uma avaliação do impacto do marco regulatório vigente para a matriz de correlação dos Key Risk Indicators (KRIs) de empresas concessionárias de geração de energia. Foi realizada uma compilação de referencial teórico relativo ao marco regulatório vigente ao qual o setor elétrico está submetido e a avaliação e identificação dos diferentes riscos do negócio, bem como a sua composição por meio de matrizes de correlação. Posteriormente, foi realizado um levantamento de dados relativos ao período de 2010 a 2015 em uma concessionária do setor elétrico, para a construção das matrizes compostas pelos indicadores sugeridos, bem como uma análise da amostra em dois subperíodos (entre 2010-2012 e 2013-2015) para mensuração da mudança do perfil de cada uma das matrizes de correlação a partir do novo marco regulatório. Por fim, foi analisada a relevância entre os resultados obtidos na correlação de cada par dos KRIs e seu embasamento com o referencial teórico apresentado, resultando em uma avaliação sobre o impacto do novo marco regulatório na matriz de correlação dos KRls em uma concessionária do setor elétrico, objeto da análise do trabalho. Os resultados indicam que para as condições de contorno estabelecidas, não é possível afirmar, com significância estatística, que o marco regulatório vigente teve impacto, de maneira generalizada, na composição da matriz de correlação dos KRls utilizados nesse trabalho, mas sim, que há indícios de impacto em alguns desses KRIs individualmente.

Palavras-chave: Setor Elétrico. Riscos. Marco Regulatório. MP 579. 


\section{Abstract \\ Impact Evaluation of the Current Regulatory Framework for KRIs' Correlation Matrix of Power Generation Industries}

This research addresses an assessment of the impact of the current regulatory framework for the correlation matrix of Key Risk Indicators (KRIs) at power generation industries, based on a review of the technical literature related to the current regulatory framework to which the electricity sector is submitted and concerning the assessment and identification of the different business risks, as well as its composition using correlation matrices. It was followed by a data collection during the period of 20102015 for the construction of matrices composed of the suggested indicators and an analysis of the sample into two sub-periods (between 2010-2012 and 2013-2015) to evaluate profile changes for each of the correlation matrices before and after the last regulatory change. Finally, the relevance of the results obtained in the correlation of each pair of KRIs and its relation to the theoretical framework presented were analyzed, resulting in an assessment of the impact of the new regulatory framework in the KRIs correlation matrix at a dealership in the electricity sector, which was the object of analysis. The results indicate that for established boundary conditions, it is not possible to state, with statistical significance, that the current regulatory framework had an impact, in a generalized way, on the composition of the correlation matrix of the KRIs used in this work, but that there is evidence of impact on some of these KRIs individually.

Keywords: Electricity Sector Risk. Regulatory. MP 579. Key Risk Indicators.

\section{Introdução}

A manutenção das concessões às empresas do setor elétrico é condicionada a completa obediência dos marcos regulatórios relativos ao seu segmento de atuação. Isto porque a concessão pública é uma forma que o Estado dispõe para transferir a um ente privado obrigações relativas à execução de um dado serviço (PRADO, 1996). De modo a regrar essa transferência de responsabilidade, o Estado dispõe de amplo arcabouço jurídico (BRASIL, 1995), além de diversas leis menores que consideram as peculiaridades de cada setor (BRASIL, 2013).

Recentemente houve mudanças significativas na forma de comercialização de energia, a partir de mudanças no marco regulatório vigente. Essa alteração legal se iniciou a partir da Medida Provisória 579/2012 (BRASIL, 2012), convertida para a Lei 12.783/2013 (BRASIL, 2013) que condicionou a renovação de concessões de usinas hidroelétricas vincendas à disponibilização integral de sua energia ao governo federal, ao mesmo tempo em que pré-definiu os montantes que seriam pagos por essa energia. Entre diversas dificuldades que o novo marco regulatório impôs aos concessionários, essa alteração impediu que contratos firmados anteriormente pudessem ser cumpridos normalmente, uma vez que parte da energia compulsoriamente disponibilizada ao governo federal já havia sido negociada com outros agentes. 
A partir da criação de Key Risk Indicators (KRI, indicadores de riscos) relativos ao novo marco regulatório (PIACENTINI, 2016), torna-se possível a mensuração de riscos envolvidos no novo cenário do setor elétrico, bem como a definição dos riscos mais relevantes e, com isso, avaliar correlações entre esses indicadores. Essas correlações indicam influências de umas variáveis em outras, o que permite que, a partir da análise desses coeficientes de correlação, sejam feitas predições de comportamentos futuros desses indicadores de forma contínua, permitindo que ações sejam tomadas para mitigar possíveis danos na continuidade operacional dos agentes do setor. As diversas correlações entre os diferentes indicadores podem ser organizadas através de uma matriz de correlação, que indicará como se comportam as correlações de cada indicador em relação a outro, dois a dois. A entrada de um novo marco regulatório pode ter alterado a composição dessa matriz, o que indica a incidência de um impacto (maior ou menor) em cada um desses coeficientes de correlação.

A continuidade operacional das concessionárias elétricas é condicionada a correta mensuração dos riscos provenientes ao novo marco regulatório. As empresas que manifestaram interesse em ter suas concessões prorrogadas compulsoriamente aceitaram uma exposição significativa ao mercado de curto prazo de comercialização de energia, em virtude da nova legislação. Essa posição, aliada ao cenário hídrico desfavorável vivenciado no Brasil recentemente, colocou em risco a viabilidade econômico-financeira das concessionárias, ao demandar a compra de energia por valores muito elevados e uma receita própria consideravelmente reduzida em relação ao planejado.

Dessa forma, o objetivo dessa pesquisa é avaliar o impacto do novo marco regulatório na matriz de correlação dos KRls de uma empresa do setor elétrico. Para isso, foram elaborados KRls a partir da literatura vigente de gestão de riscos e considerando dados da empresa CEEE-GT (Companhia Estadual de Energia Elétrica - Geração/Transmissão), sendo essa uma empresa de economia mista, que detém a concessão de serviços de geração e transmissão de energia elétrica no estado do Rio Grande do Sul. O presente trabalho está apresentado em oito capítulos. O primeiro capítulo apresentará uma introdução sobre o tema a ser abordado, juntamente com uma apresentação do problema de pesquisa e os objetivos que busca atingir. Os quatro capítulos posteriores irão apresentar a fundamentação teórica em que a análise do trabalho será desenvolvida, compreendendo: um panorama das teorias sobre os diferentes riscos e seus conceitos; as diferentes formas de contratação de energia (Ambiente de Contratação Regulado, ACR e Ambiente de Contratação Livre, ACL); o último marco regulatório do setor elétrico, assim como uma breve descrição da CEEE-GT e, por fim, um breve conceito de key risk indicators (KRIs) e correlação. O capítulo posterior apresentará o método aplicado, a tipificação da pesquisa e os motivos que levaram ao desenvolvimento da mesma.

Após será realizada uma comparação entre as matrizes de correlação dos KRls antes e depois da mudança legal para renovação de concessões. Essa comparação será feita a partir de indicadores criados para avaliar os diferentes riscos (financeiro, operacional e regulatório) presentes no negócio a partir de dados internos da companhia. Esses indicadores serão mensurados para o período de 2010 a 2015, sendo avaliados em dois subperíodos, de 2010-2012 e 2013-2015, buscando identificar mudanças na estrutura de sua matriz de correlação em cada um desses subperíodos, que possam ser explicadas pela aplicação do novo marco regulatório. Por fim, o último capítulo irá conter 
algumas considerações finais em relação esse artigo, bem como limitações consideradas e dificuldades encontradas, bem como sugestões para pesquisas complementares sobre o tema.

\section{Riscos e o Setor Elétrico}

Há grande relevância na correta avaliação de riscos para empresas do setor elétrico, em especial para as estatais. Porém, não é apenas na transparência e na estrutura das empresas estatais que se podem identificar benefícios para a gestão de riscos, uma vez que a definição formal de normas, processos e estruturas promove a resiliência das companhias às mudanças nos ambientes operacionais e corporativos, reduzindo riscos operacionais e permitindo a realização de objetivos (BOVESPA, 2015). Os riscos que o setor elétrico se encontra exposto podendo ser divididos em:

Risco regulatório - envolve os riscos políticos e os riscos legais referentes a todo o negócio do setor elétrico. Qualquer movimentação política que altere os valores e/ou resultados esperados de uma dada ação econômica através da alteração das probabilidades de atingir os objetivos do negócio pode ser caracterizado como risco político ( $\mathrm{PwC}, 2006)$, enquanto o risco legal faz referência a probabilidade de que uma determinada transação ou atividade de um processo não possa ser concluída em virtude de alguma barreira legal, como documentação inadequada, não cumprimento de definições regulatórias e a falta de possibilidade de cobrar garantias em caso de falência bancária (JORION, 2003).

Risco operacional - A definição de risco operacional não é tão direta como a de outros tipos de risco, como o de mercado e o de crédito, mas pode ser definido de forma ampla como o risco de perda, direta ou indireta, derivado da inadequação ou falha de processo interno, sistema, pessoa ou evento externo (JORION, 2003; ASSI, 2012), como por exemplo risco de overload, risco de obsolescência, risco de equipamento, risco de erro não intencional, risco de fraude, risco de qualificação, risco de produtos ou serviços, risco de regulamentação, risco sistêmico e risco de catástrofe (ASSI, 2012).

Risco financeiro - consiste nos riscos de liquidez, risco de mercado e risco de crédito, mais comumente utilizados em setores financeiros. O risco de liquidez de uma instituição diz respeito ao risco dela não ser capaz de honrar seus compromissos financeiros prontamente à medida que vencem, sem incorrer em perda substancial (SAUNDERS, 2000), e, conforme Resolução 2.804/2000 do Banco Central do Brasil, esse risco decorre do "descasamento" entre pagamentos e recebimentos da instituição, ocasionado pelos diferentes ativos e passivos, com relação às suas diferentes moedas $\mathrm{e}$ prazos de liquidação (MASTELLA, 2008). Por outro lado, a mensuração do risco de mercado tem por objetivo quantificar o risco de perdas devido a oscilações de variáveis do mercado financeiro, que incluem taxa de juros, taxa de câmbio, capital próprio e commodities, com posições que podem incluir caixa ou derivativos (JORION, 2003). Por fim, o risco de crédito indica a perda financeira que pode ocorrer a partir do não cumprimento das obrigações contratuais de uma das partes envolvidas na negociação. Seu efeito é mensurado pelo custo de troca dos fluxos de caixa se a outra parte entra em default, e envolve a possibilidade de não pagamento de uma obrigação futura ou em uma transação efetiva (JORION, 2003). 


\section{Métodos de Contratação de Energia}

O setor elétrico brasileiro possui diferentes formas de contratação de energia elétrica, padronizadas de acordo com as características dos agentes envolvidos, do prazo de fornecimento da energia, do nível de tensão e da demanda a ser contratada; estas formas se caracterizam no Ambiente de Contratação Livre (ACL) e o Ambiente de Contratação Regulada (ACR).

No ACL, os agentes interessados em realizar um processo de compra e venda de energia negociam livremente entre si, estabelecendo valores e condições para a transação através de contratos bilaterais que formalizam as condições acordadas. No ACL, o preço da energia é negociado entre a Comercializadora ou o consumidor final de forma livre, ficando sujeito a alterações de mercado (custos de produção, regimes hidrológicos, aumento de demanda, etc) e com período de contrato que pode ser de curto, médio e longo prazo, de acordo com o interesse das partes (BRASIL, 2004a; BRASIL, 2004b).

Por outro lado, o ACR possui características distintas, já que a comercialização de energia é feita através de leilões, chamados "Leilão de Energia Nova (LEN A-3), para início de fornecimento em 3 anos, Leilão de Energia Nova (LEN A-5), para início de fornecimento em cinco anos, Leilão de Energia Nova de Fontes Alternativas (LEN FA) e do Leilão de Energia de Reserva (LER). Esses LeiIões são promovidos pelo MME/ANEEL/EPE e operados pela CCEE". Os preços máximos desses leilões são definidos pela ANEEL, através de resolução, e cada empreendedor interessado em participar do certame oferta lances com valores obrigatoriamente menores ao preço máximo, sendo que o leilão se encerra quando a oferta de energia se igualar a demanda.

Uma comparação entre a dinâmica de contratação no ACR em relação ao ACL pode ser vista na figura abaixo:

Figura 1 - Contratação via ACR vs ACL

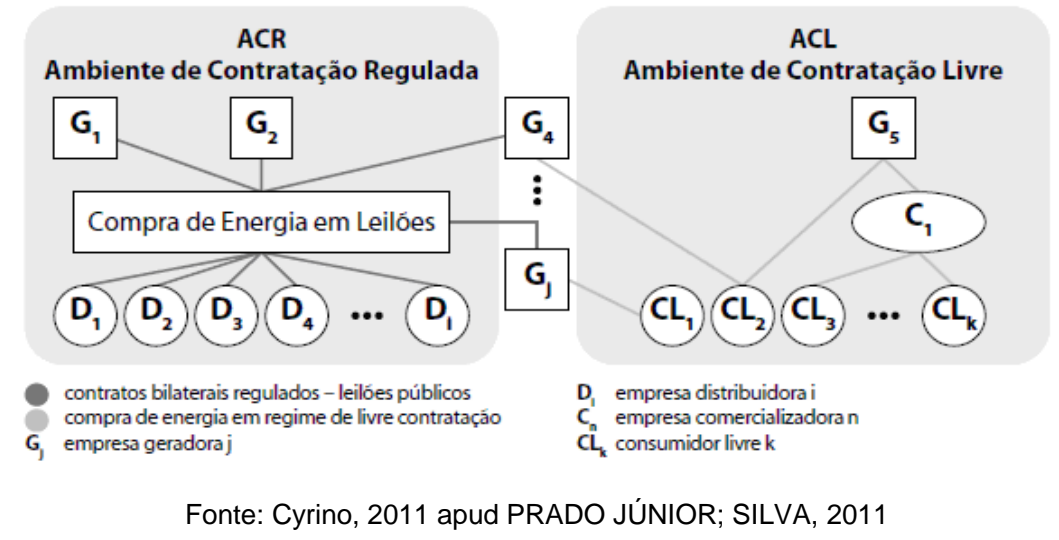

Nessa figura, vemos que toda a energia demandada pelas distribuidoras é adquirida através de contratos regulados, firmados através de leilões públicos entre as distribuidoras e as concessionárias geradoras pelo ACR. Em contrapartida, os consumidores livres são autorizados a adquirir energia diretamente das concessionárias geradoras, bem como das empresas comercializadoras, através de livre contratação, regulada pelo ACL. 


\section{Marcos Regulatórios do Setor Elétrico}

O setor elétrico brasileiro é regulado através da Agência Nacional de Energia Elétrica (ANEEL), que determina a forma como será gerada, transmitida, distribuída e comercializada a energia elétrica no Brasil. No ano de 2012, o governo federal decidiu regular a situação da renovação das concessões através da Medida Provisória 579 (MP 579). Nela, permitiu-se que as concessões vincendas em 2015 fossem renovadas em 2013 por 30 anos, através de um novo regramento. Para as Geradoras, foram calculados os valores de energia equivalentes aos custos de operação e manutenção de cada uma das usinas que seriam renovadas, sendo que a totalidade de sua produção deveria ser destinada ao mercado regulado através de um regime de participação de quotas para as empresas de distribuição. Adicionalmente, alguns encargos do governo foram retirados da tarifa, sendo que parte dos recursos perdidos a partir dessa retirada seria coberto por aportes do tesouro (estimados inicialmente em $\mathrm{R} \$ 3,3$ bilhões), visando uma redução nas tarifas a partir de uma contratação de longo prazo pelas Distribuidoras.

Em contrapartida, todo e qualquer ativo não amortizado até janeiro de 2013 deveriam ser pagos à vista, para que não houvesse mais ativos não amortizados em operação após essa data. Para essa despesa, seriam utilizados valores existentes na conta de Reserva Global de Reversão, que segundo o governo seriam suficientes para tal (opinião não compartilhada por alguns analistas). Por fim, a MP definiu também um rígido cronograma de adesões por parte dos interessados em um período de 35 dias após sua publicação. As concessionárias que não aderissem às novas regras poderiam manter sua concessão até a data de vencimento, conforme regras anteriores à MP 579, mas, após esse período, deveriam devolver as mesmas para nova licitação. Destaca-se que a opção de aderir ou não ao novo programa de renovação das concessões deveria ser feita antes que fossem publicadas as tarifas a serem pagas para O\&M, os valores a serem indenizados os ativos não amortizados e a forma de alocação de quotas (PRADO JÚNIOR; SILVA, 2011).

Após a aplicação dessas medidas, as tarifas pagas para as concessionárias ficaram, em média, 1/3 dos valores que eram praticados anteriormente. Além disso, houve expressiva redução do valor de mercado das companhias do setor elétrico (verificado através dos valores de suas ações), anúncios de redução no quadro de pessoal das empresas afetadas, questionamento da legalidade de várias das ações propostas pela MP 579, redução no volume de impostos arrecadado pelos Estados, redução no montante de energia disponível para comercialização no Mercado Livre e uma insuficiência de informações e tempo para avaliação dos impactos dessas medidas pelas concessionárias antes de tomar a decisão de renovar ou não suas concessões (PRADO JÚNIOR; SILVA, 2011).

\section{Indicadores-chave de risco e Matriz de Correlação}

Os KRI são ferramentas de gestão mensuráveis, que permitem monitorar corretamente riscos. Esses indicadores (na maior parte das vezes expresso em quantidades, percentuais ou relações) fornecem informações a respeito da exposição ao risco (impacto multiplicado por sua probabilidade de ocorrência) pois indicam se o perfil de risco foi ou está se modificando. Os valores dos KRI são monitorados em valores absolutos e, também, comparados a tendências. Eles são rastreados em 
relação a um limite específico, chamado tolerância ao risco (o nível aceitável de variação relativo ao atingimento de objetivos). A operação dentro dos níveis de tolerância ao risco indica a gestão de que a entidade permanece operando dentro do seu apetite a risco o que, por sua vez, proporciona um certo grau de conforto que a entidade irá atingir seus objetivos, sem extrapolar seus limites de exposição ao risco. Dessa forma, os KRIs não mensuram risco, mas determinam o "quão arriscado" é (DELOITTE, 2014).

Em um estágio mais avançado de análise de riscos, torna-se relevante considerar a interdependência entre variáveis, expressa pela correlação estatística, que indica a existência de influência da variável A sobre a variável $B$, e vice-versa (TAMAROZI, 2002). Scarlat, Chirita e Bradea (2012) avaliam que ao definir um mapa de riscos de um empreendimento, o risco mais relevante de cada setor deve ser escolhido e que correlações devem ser traçadas entre eles

\section{Materiais e Métodos}

A pesquisa é tipificada como quantitativa, aplicada, descritiva, documental; é quantitativa pois utilizará dados brutos e mensuráveis para a análise e validação dos pressupostos adotados; é aplicada porque busca solução de um problema específico; descritiva, uma vez que descreve uma situação real para, a partir dessa descrição, avaliar um fato e documental pois irá se basear em documentos distintos, como tabelas e relatórios, entre outros (GERHARDT; SILVEIRA, 2009), sendo que a obtenção dos dados teve como base relatórios desenvolvidos pela CEEE-GT.

A mensuração do possível impacto do marco regulatório na matriz de correlação dos KRls será feita a partir dos indicadores desenvolvidos por Piacentini (2016), resumidamente descritos abaixo:

Quadro 1 - Resumo dos indicadores adotados

\begin{tabular}{|c|c|c|c|c|}
\hline Indicador & $\begin{array}{c}\text { Conceito abordado } \\
\text { pelo indicador }\end{array}$ & $\begin{array}{c}\text { Houve dife- } \\
\text { rença } \\
\text { entre médias? }\end{array}$ & $\begin{array}{c}\text { Resultado relacionado com o } \\
\text { marco regulatório? }\end{array}$ & Tendência \\
\hline IFI1 & Montante da dívida & Sim & Não & $=$ \\
\hline IFI2 & Custo médio da dívida & Sim & Não & $=$ \\
\hline IFI3 & Saldo de caixa & Não & Não & $=$ \\
\hline IOP1 & Acidentes de trabalho & Não & Sim & $\uparrow$ \\
\hline IOP2 & Falhas em usinas & Sim & Não & $\uparrow$ \\
\hline IOP3 & Ações trabalhistas & Não & Não & $=$ \\
\hline IOP4 & Horas extras & Sim & Sim & $\downarrow$ \\
\hline IRE1 & Receita com energia vendida & Sim & Sim & $\uparrow$ \\
\hline IRE2 & Exposição no mercado & Não aplicável & & $\uparrow$ \\
\hline
\end{tabular}

Esses indicadores foram criados a partir de dados levantados entre 2010 a 2015, por meio de relatórios emitidos pela CEEE, sendo que o período amostrado foi estratificado em dois sub-períodos, divididos em janeiro de 2013, sendo o primeiro período pré-marco legal e o segundo pós marco legal sendo os dados convertidos em número índice (com base set/2012=1). Posteriormente foi realizada uma análise estatística de diferença entre médias, buscando identificar diferenças entre os dois períodos (o primeiro de janeiro de 2010 a dezembro de 2012 e o segundo de janeiro de 2013 a dezembro de 2015) (HAIR, 2009). Com base nos dados obtidos nesse teste, foram analisadas as relações dos 
resultados encontrados com a fundamentação teórica desse trabalho, buscando identificar indícios de correlação com as diferenças entre as sub-amostras (quando essas de fato ocorreram) e a implementação do novo marco legal.

A partir dos indicadores compostos pelo método descrito acima, foram elaboradas duas matrizes de correlação, uma para o primeiro subperíodo e outra para o segundo. Cada uma delas indica a correlação de cada índice para todos os demais, dois a dois. Essas matrizes utilizaram apenas os indicadores considerados relevantes (apresentaram relação com o marco legal e/ou apresentaram tendência de aumento ou diminuição entre os dois períodos, e a partir da comparação entre as correlações apresentadas em cada subperíodo, pretende-se avaliar se o marco regulatório teve influência na mudança do comportamento das correlações entre os KRIs.

Com base nesses parâmetros, foram elencados os seguintes KRIs para análise: IFI1, IFI2, IFI3, IOP2 (dividido em A e B, sendo o primeiro o KRI que mensura a quantidade de horas de indisponibilidade por falhas nas usinas e o segundo a quantidade de eventos geradores de indisponibilidade por falhas), IOP3, IOP4 e IRE1. Apesar do indicador IRE2 ser relevante para a pesquisa, não foi possível realizar sua avaliação pois o mesmo não existia antes do marco regulatório.

\section{Resultados e Discussão}

Nesse capítulo serão apresentadas as matrizes de correlação dos KRIs para os dois subperíodos avaliados, construídas conforme detalhado no capítulo do método, visando identificar se há evidência de impacto da mudança no marco regulatório na configuração dessas matrizes de correlação. Essa matriz de correlação foi gerada utilizando o software Gretl e foram testadas as significâncias dos elementos da matriz considerando um erro de $5 \%$, sendo esses indicados com um asterisco $\left({ }^{*}\right)$. Os resultados podem ser vistos na tabela 1 , abaixo:

Tabela 1 - Matrizes de correlação pré e pós marco regulatório

\begin{tabular}{|c|c|c|c|c|c|c|c|c|}
\hline \multicolumn{9}{|c|}{ Painel 1: dados pré marco regulatório, 2010-2012 } \\
\hline IFI1 & IFI2 & IFI3 & IOP2A & IOP2B & IOP3 & IOP4 & IRE1 & \\
\hline \multirow[t]{8}{*}{1} & $-0,6285^{\star}$ & 0,2042 & 0,0734 & 0,1135 & 0,179 & $0,7851^{*}$ & $-0,9446^{*}$ & IFI1 \\
\hline & 1 & $-0,1788$ & $-0,2845$ & $-0,4046^{*}$ & $-0,3915^{*}$ & $-0,6122^{*}$ & $0,6503^{*}$ & IFI2 \\
\hline & & 1 & 0,0987 & $-0,1494$ & $-0,0065$ & 0,013 & $-0,1554$ & IFI3 \\
\hline & & & 1 & 0,4566 & 0,1036 & 0,1255 & 0,0129 & IOP2A \\
\hline & & & & 1 & 0,0606 & $0,3588^{*}$ & $-0,0373$ & IOP2B \\
\hline & & & & & 1 & 0,3129 & $-0,1346$ & IOP3 \\
\hline & & & & & & 1 & $-0,7049^{*}$ & IOP4 \\
\hline & & & & & & & 1 & IRE1 \\
\hline \multicolumn{9}{|c|}{ Painel 2: dados pós marco regulatório, 2013-2015 } \\
\hline IFI1 & IFI2 & IFI3 & IOP2A & IOP2B & IOP3 & IOP4 & IRE1 & \\
\hline \multirow[t]{8}{*}{1} & $0,4902^{*}$ & $-0,4028^{*}$ & 0,0328 & 0,2653 & $0,5568^{*}$ & $-0,2519$ & 0,0695 & IFI1 \\
\hline & 1 & $-0,421^{*}$ & 0,1032 & 0,1598 & $0,6484^{*}$ & $-0,0442$ & $0,3459^{*}$ & IFI2 \\
\hline & & 1 & $-0,3861^{*}$ & $-0,3799^{*}$ & $-0,4128^{*}$ & 0,0905 & $0,3474^{*}$ & IFI3 \\
\hline & & & 1 & 0,2535 & 0,1302 & 0,0075 & $-0,4522^{*}$ & IOP2A \\
\hline & & & & 1 & 0,2021 & 0,2014 & 0,1114 & IOP2B \\
\hline & & & & & 1 & $-0,0882$ & 0,0233 & IOP3 \\
\hline & & & & & & 1 & $-0,0219$ & IOP4 \\
\hline & & & & & & & 1 & IRE1 \\
\hline
\end{tabular}


O primeiro painel da tabela 1 apresenta as correlações ocorridas entre os KRIs para o período de 2010 a 2012, sendo que entre os valores que apresentaram significância estatística, destacamse a correlação entre IOP4 versus IFI1 $(0,7851)$, IRE1 versus IFI2 $(0,6503)$, as duas maiores correlações positivas e IRE1 versus IFI1 $(-0,9446)$ e IRE1 versus IOP4 $(-0,7049)$, as duas maiores correlações negativas.

Entre os indicadores com correlação positiva, a correlação de IOP4 versus IFI1 indica que há uma correlação direta e forte, segundo parâmetros estabelecidos por Callegari-Jacques (2009), entre esses KRIs, o que aponta que um aumento nas horas extras estaria fortemente relacionado ao aumento da dívida total. Esse resultado parece factível se assumirmos um cenário em que a empresa referida necessita financiar-se para cobrir um incremento de despesas, como a proveniente com horas extras. A correlação de IRE1 versus IFI2 também indica que há uma correlação direta e forte entre os indicadores, o que aponta que um aumento de receita com energia vendida esta relacionado com o aumento do custo da dívida.

Já para os indicadores com correlação negativa, a correlação de IRE1 versus IFI1 indica que existe uma correlação inversa e muito forte entre esse par de KRIs, o que aponta que um aumento na receita com energia vendida estaria relacionado com uma redução da dívida total. Esse resultado parece factível se assumirmos um cenário em que a empresa referida aumenta o seu fluxo de pagamento da dívida a partir do aumento de receita obtida com a energia vendida. A correlação de IRE1 versus IOP4 indica uma correlação inversa e forte entre o par IRE1 versos IOP4, o que indica que um incremento de receita com energia vendida teria relação com a redução da quantidade de horas extras.

O segundo painel da tabela 1 apresenta as correlações ocorridas entre os KRls para o período de 2012 a 2015, sendo que entre os valores que apresentaram significância estatística, destacamse a correlação entre IOP3 versus IFI1 $(0,5568)$, IOP3 versus IFI2 $(0,6484)$, as duas maiores correlações positivas e IFI3 versus IFI2 $(-0,421)$ e IRE1 versus IOP2A $(-0,4522)$, as duas maiores correlações negativas. Entre os indicadores com correlação positiva, a correlação de IOP3 versus IFI1 indica uma correlação moderada e direta, o que aponta para um aumento no número de ações trabalhistas ingressadas contra a empresa relacionada a um aumento da dívida total. Esse resultado parece factível se assumirmos um cenário em que a empresa referida necessita financiar-se para cobrir um incremento de despesas, como o de ações trabalhistas. A correlação de IOP3 versus IFI2 apresenta a hipótese de relacionamento direto e forte, o que se traduziria que um aumento de ações trabalhistas estaria relacionado ao aumento do custo da dívida. Esse valor também parece factível para um cenário em que a empresa necessita se financiar para honrar os custos de ações trabalhistas, e seu crédito no mercado encontra-se restrito, fazendo-se necessário recorrer a produtos financeiros de maior custo.

Já para os indicadores com correlação negativa, a correlação de IFI3 versus IFI2 apresenta uma relação inversa e moderada, apontando que um aumento no saldo de caixa poderia estar relacionado a redução do custo da dívida. Esse resultado parece factível se assumirmos um cenário em que a empresa referida utiliza um aumento no saldo de caixa para quitar parte de sua dívida. É esperado que as dívidas com maior custo sejam priorizadas frente as de menor custo, portanto a redução 
no custo da dívida é plausível. Da mesma forma, a correlação de IRE1 versus IOP2A também apresenta uma correlação moderada e inversa, o que leva a crer que um incremento de receita com energia vendida estaria relacionado a redução da quantidade de horas de indisponibilidade por falhas. Esse valor parece factível, uma vez que ao obter uma maior receita com energia vendida, a empresa poderia despender uma quantia maior para a manutenção de seus ativos, fazendo com que as falhas fossem resolvidas mais rapidamente, reduzindo o tempo de indisponibilidade.

Comparando os resultados entre os dois painéis, é possível identificar que apenas uma pequena parcela dos KRIs manteve significância estatística entre os dois períodos, sendo eles os seguintes: IFI2 versus IFI1 (-0,6285 e 0,4902 para o período 1 e 2 , respectivamente), IOP3 versus IFI2 (-0,3915 e 0,6484 respectivamente) e IRE1 versus IFI2 (0,6503 e 0,3459 respectivamente). Em todos os casos em que houve manutenção da significância estatística dos valores, é possível perceber uma mudança na estrutura da correlação entre os pares.

No caso de IFI2 versus IFI1, os pares apresentavam uma relação de dependência inversa e forte durante o período pré marco regulatório, o que se modificou tanto em magnitude quanto em sentido, passando a apresentar uma relação direta e moderada. O par IOP3 versus IFI2 também apresentava uma correlação inversa e moderada no período pré marco regulatório, o que no período pós marco regulatório passou a ser uma relação de dependência forte e direta. Por fim a mudança identificada na correlação de IRE1 versus IFI2 foi apenas na magnitude, pois manteve-se uma relação de dependência direta nos períodos pré e pós marco regulatório mas observou-se mudança em sua magnitude, registrada na redução na intensidade dessa relação, que era forte no primeiro momento e passou a ser moderada no segundo.

Durante o período pré marco regulatório, os seguintes pares tinham significância estatística, para um erro de $5 \%$, mas não a mantiveram durante o período pós marco regulatório: IOP4 versus IFI1; IRE1 versus IFI1; IOP2B versus IFI2; IOP4 versus IOP2B e IRE1 versus IOP4. Já para o período pós marco regulatório os seguintes pares apresentaram significância estatística, sem que a tivessem durante o período pré marco regulatório: IFI3 versus IFI1; IOP3 versus IFI1; IFI3 versus IFI2; IOP2A versus IFI3; IOP2B versus IFI3; IOP3 versus IFI3; IRE1 versus IFI3 e IRE1 versus IOP2A.

Dessa forma não é possível afirmar, com significância estatística, que o marco regulatório vigente teve impacto, de maneira geral, na composição da matriz de correlação dos KRls elencados no quadro 1, no que trata da composição de riscos de uma concessionária de geração do setor elétrico. Porém, houve indício de impacto em alguns dos KRls que compõe essa matriz, como por exemplo os pares IFI2 versus IFI1, IOP3 versus IFI2 e IRE1 versus IFI2. Ainda, cabe ressaltar que os resultados obtidos não indicam relação de causa-efeito, mas, sim, de relação presumida entre as variáveis apresentadas.

\section{Considerações Finais}

O principal objetivo do presente trabalho era identificar o impacto do marco regulatório vigente na composição da matriz de correlação dos KRIs em uma concessionária de geração do setor elétrico. Entende-se que o objetivo proposto foi atingido, pois a partir dos resultados obtidos na observa- 
ção das matrizes de correlação dos KRls antes e depois da implementação do marco regulatório vigente, foi possível identificar que, para as condições de contorno estabelecidas, não é possível afirmar, com significância estatística, que o marco regulatório vigente teve impacto, de maneira generalizada, na composição da matriz de correlação dos KRls utilizados nesse trabalho mas sim, que há indícios de impacto em alguns desses KRls individualmente.

Entre as principais dificuldades encontradas no processo de pesquisa, pode se destacar a falta de transparência no que se refere a dados da companhia, o que gerou grande dificuldade na obtenção dos dados. Além disso, a avaliação de riscos no setor elétrico se mostrou complexa, pois além das especificidades do setor, a quantidade de material acadêmico disponível (em especial de pesquisas quantitativas) se mostrou inferior ao esperado, o que mostra excelente campo para pesquisas futuras.

Entre as limitações da pesquisa encontram-se a volatilidade em que atualmente encontra-se o setor elétrico, pois já existem outras alterações propostas para o marco regulatório vigente. Dessa forma, nem todos os resultados obtidos nesse trabalho poderão ser integralmente utilizados, dependendo dos resultados que algumas propostas de alteração no marco regulatório possam vir a ter. Outra limitação está na quantidade de indicadores com significância estatística disponíveis para comparação, em face da margem de erro proposta nessa pesquisa.

A expansão da pesquisa aplicada nesse trabalho a partir da análise de defasagens dos indicadores propostos é uma sugestão para trabalhos futuros, pois pode ser observado que alguns desses KRls apresentarão sua influência na correlação dos demais em um período diferente do atual (como, por exemplo o IOP3, que mede quantidade de ações trabalhistas ingressadas contra a companhia e pode ter seu impacto na correlação com outros KRIs apenas alguns anos depois, tendo em vista o tempo de trânsito que essas ações tem antes de sua efetiva conclusão). Outro ponto que pode ser abordado em um trabalho futuro é a expansão da margem de erro utilizada nesse trabalho ( $\alpha=5 \%)$ para um índice maior, de forma a obter uma maior quantidade de KRls estatisticamente significantes e, assim, permitir a comparação entre mais pares, propiciando uma análise mais abrangente do que a que foi realizada.

\section{Referências}

BOVESPA. Programa destaque em governança de estatais, de 30 de setembro de 2015. Disponível em: <http://www.bmfbovespa.com.br/pt_br/listagem/acoes/governanca-de-estatais/ $>$ Acesso em: 25 abr. 2016.

BRASIL. Portaria GM no 3.214, de 08 de Junho de 1978. Disponível em: <http://www.mtps.gov.br/images/Documentos/SST/NR/NR4.pdf> Acesso em: 18 abr. 2016.

BRASIL. Decreto no 5.163, de 30 de Julho de 2004. Disponível em: <http://www.planalto.gov.br/ccivil_03/_ato2004-2006/2004/decreto/d5163.HTM > Acesso em: 19 nov. 2015.

BRASIL. Lei no 8.987, de 13 de Fevereiro de 1995 . Disponível em: <http://www.planalto.gov.br/ccivil_03/LEIS/L8987cons.htm> Acesso em: 19 nov. 2015. 
BRASIL. Lei no 10.848, de 15 de Março de 2004. Disponível em: < https://goo.gl/GXvQN9 > Acesso em: 19 nov. 2015.

BRASIL. Lei no 12.783, de 11 de Janeiro de 2013. Disponível em: < https://goo.gl/3hUFkQ >htm Acesso em: 19 nov. 2015.

BRASIL. Medida Provisória no 579, de 11 de Setembro de 2012. Disponível em: <http://www.planalto.gov.br/ccivil_03/_ato2011-2014/2012/mpv/579.htm >Acesso em: 19 nov. 2015.

CALLEGARI-JACQUES, S. M. Bioestatística: princípios e aplicações. Porto Alegre: Artmed, 2009.

DELOITTE. Risk Intelligence in the Energy \& Resources Industry: Enterprise Risk Management Benchmark Survey Report, 2013. Disponível em: < https://goo.gl/9ZK8Hj >Acesso em: 10 jun. 2012.

GERARD, T. E.; SILVEIRA, D. T. (Org). Métodos de Pesquisa: Planejamento e Gestão para o Desenvolvimento Rural da SEAD/UFRGS. Porto Alegre: Editora da UFRGS, 2009.

GROTTI, D. A. M. A experiência brasileira nas concessões de serviço público. Interesse Público, Belo Horizonte, v. 9, n. 42, mar. 2007. Disponível em: <http://bdjur.stj.jus.br/dspace/handle/2011/38544. > Acesso em: 02 dez. 2015.

HAIR JÚNIOR, J. F. et al. Análise multivariada de dados. 6. ed. Porto Alegre: Bookman, 2009.

JUSTEN FILHO, M. Curso de direito administrativo. 10 ed. São Paulo: Editora Revista dos Tribunais, 2014.

MASTELLA, M. Um modelo de gerenciamento de risco de liquidez para o contexto brasileiro. Dissertação (Mestrado). Universidade Federal do Rio Grande do Sul. Escola de Administração. Programa de Pós-Graduação em Administração. Porto Alegre, 2008. Disponível em: <http://www.lume.ufrgs.br/handle/10183/12743> Acesso em: 10 jun. 2016.

PRADO JÚNIOR. F. A. de A.; SILVA, A. L. R. da. Sobre reformas e concessões no setor elétrico brasileiro: uma análise crítica. Revista Estratégica, v.11, n.2, p.85-115, São Paulo, 2011. Disponível em: <http://estrategica.faap.br/ojs/index.php/estrategica/article/view/10/7> Acesso em: 16 nov. 2015.

PRADO, M. Concessão Pública: um empreendimento público comercial. Revista do BNDES, v.3, n.5, p105-126, Rio de Janeiro, 1996. Disponível em: < https://goo.gl/aQK7XN > Acesso em: 19 nov. 2015.

PRICE WATERHOUSE COOPERS - How energy companies can improve global business performance by better managing political risk. 2006. Disponível em: <http://www.pwc.com/us/en/risk-compliance.html > Acesso em: 26 abr. 2016.

SCARLAT, E.; CHIRITA, N.; BRADEA, I. A. Indicators And Metrics Used In The Enterprise Risk Management - 2012.2 Disponível em: <www.ecocyb.ase.ro/20124pdf/Emil\%20Scarlat\%20(T).pdf> Acesso em: 10 jun. 2016.

TAMAROZI, R. Identificação, modelagem e mitigação de riscos em operações de comercialização de energia elétrica no mercado brasileiro. 2002. Tese (Doutorado). Universidade Federal do Paraná. Programa de Pós-Graduação em Engenharia de Recursos Hídricos e Ambiental, do Setor de Tecnologia. Paraná, 2002. Disponível em: < http://www.abraceel.com.br/_anexos/teseriscoscomercializacao.pdf > Acesso em: 10 jun. 2016. 